\title{
ALFREDO ARMAS ALFONZO: LAS ALAS DEL ÁNGEL
}

POR

Luis BRITto GaRcía

Ay, Tomás, que es preferible que a uno le nazcan adentro cualquier cosa menos las alas del ángel por fuera. Tú no ves que son tan frágiles que se rompen con la primera ventolera.

Alfredo Armas Alfonzo: Los desiertos del ángel.

El ÁNGEL - DEL CRIOLLISMO A LA VISIÓN

Una crónica pueblerina inventarió los objetos de la ruralidad latinoamericana. La crítica los descalificó llamándolos temas del criollismo. Para el gusto exquisito, no debían ser abordados jamás: el campo, las eminencias aldeanas, los dos oficios de la cotidianidad: eran lo vulgar, lo ya visto. Pero ¿habían sido alguna vez mirados?

Pues el ojo del naturalista sólo había descubierto en ellos fealdades, el del panfletista político miserias, el del positivista, barbaries, y el del esteta, paisajes. No mentían, aproximación de un narrador - letrado, modernizante, eurocéntrico y reformista - a una teluricidad a la que representaba como primaria. A mediados de este siglo tal disyunción entre narrador y tema coaguló en relatos que transmitían, mediante retórica hiperculta, versiones tremendistas de una realidad donde no había personaje que no fuera mutilado o agonizante o idiota, ni tierra que no fuera devoradora. La caracterización de la naturaleza como Madre Terrible o Reino de la Muerte se impuso desde las ciudades que la expoliaban.

Alfredo Armas Alfonzo anduvo en sus relatos juveniles en los alrededores de este enfoque. Pero por esa época hizo suyo el lema de Unamuno: para dar en el clavo, hay que golpear cien veces en la herradura. De tanto arrancarle chispas al yunque de la memoria, obtuvo también luz. A partir de cierto momento, en su narrativa ya no hay esa disyunción entre forma hiperculta y sujeto hiperdestruido, esa separación entre narrador civil y naturaleza salvaje. Una prosa a la vez coloquial y clásica, en la cual las inflexiones y entonaciones populares no aparecen como interferencias, sino como una segunda naturaleza; elimina toda oposición entre lo narrado y el narrador. Este último encuentra por fin sitio adecuado y armonioso en su universo. En otras palabras, resuelve, por la vía literaria, el problema de nuestra compleja y contradictoria identidad. Pues ya no son antagónicos texto y contexto. De tal manera, y por procedimientos que no pretendo esclarecer totalmente, el enfoque se transforma en visión. 


\section{LOS CIELOS DE LA TOTALIDAD}

Alfredo Armas Alfonzo, que yo recuerde, jamás recurre a la metáfora del ojo: por esta omisión, es quien la realiza más plenamente. Pues el ojo está condenado a no verse jamás a sí mismo, salvo por reflejo o simulacro. Esta autonegación le permite contener el universo, aunque sólo sea a través de los transitorios hitos de la captación y el desvanecimiento de las imágenes. Su segunda paradoja es la de que sólo cuando el párpado lo cubre comienza el ultimo agobio de su poder: ocluido el chisporroteo de la vista, se enciende la plenitud de la visión: algo más íntegro y por tanto más lacerante que fealdad, miseria, esquema o paisaje. Ya que todo mirar es parcial y se confina al enfoque: sólo en el trance visionario encontramos esa totalidad cuyo correlato literario es la obra abierta.

Ya no podemos acercarnos a las soledades de Clarines sin sentir una ebullición de presencias. El arte ha cumplido allí su función de hacer visible lo invisible, de superponer a lo real una penetración más profunda. El pueblo natal de Armas Alfonzo y sus alrededores son ya tierra de leyendas: lo que significa que sólo podemos acercarnos a ella con los ojos cerrados. únicamente así las inoportunas correciones de la realidad no perturbarán una forma perdurable instalada por vías de lo imaginario. Todas las posibilidades de cada destino refulgen y se agotan a la vez en esa docena de líneas que equivalen a un latido y a una existencia. Masas humanas carecen, se infligen daño o goce, se acomodan a su suerte o se rebelan contra ella con gestos escuetos que siempre parecen inmediatamente apagados por un olvido feroz y por eso duelen largamente, como heridas. Ningún esquema va a explicarnos por qué trascienden más allá del dato tantas anécdotas menudas de gente confundida con arena, que ni siquiera llegaron a datos. En estos relatos mínimos y multitudinarios como polvo espejean presencias cegadoras como ángeles; es sobre la sequedad del desierto donde relumbra el espejismo: la ilusión de que la mísera trivialidad terrena participa de la fluidez de los vientos y de la incandescencia de la luz. Si de tal aridez queda un vapor, será de nubes. La nube es siempre la misma, porque ninguna permanece. La férrea dictadura de lo imaginario la convirtió en morada del ángel. La atroz precariedad de la existencia convidó a creer que por cada ser vela un espíritu alado. Quizá no lleguemos a tanto: apenas uno que otro ser elegido tendrá derecho a una nube: a una memoria.

\section{EL OSARIO DE LA PERENNIDAD}

Alfredo Armas Alfonzo casi nunca ha trabajado el contrapunto de planos temporales distintos en un mismo relato. Y sin embargo sus visiones han quedado superpuestas en lo perenne. En el recuerdo, hileras de sus personajes se teje, se entrelazan y se funden: una escarapela blanca se pudre interminablemente sobre flores que retoñan o se marchitan y centenares de sapos ciegos chapotean entre los humores de sus ojos reventados. Siempre parece que Merceditas Alfonzo estuvo en una ventana viendo partir o llegar a alguien. Quizá, como el Corán, estuvo allí desde antes de la Creación, en la que tantos creen sólo como justificación o ejemplificación de un libro. Porque para la visión total no hay decurso del tiempo, y todo futuro, presente y pasado son unánimemente actuales. 
Ello no es mero efecto o defecto de la memoria. Armas Alfonzo evita la prolongada construcción de un clímax, ese equivalente literario de la manipulación de la perspectiva en el dibujo renacentista (que, con su delirio de profundidad emblematiza el tiempo, según Oswald Spengler). En un sólo párrafo, cubre dolientes travesías en el devenir que a otros autores le llevarían libros. $\mathrm{O}$, desde el comienzo, anuncia de una vez y sin misterio alguno el desenlace que luego elaborará durante toda una obra. A veces, por ejemplo en Este resto de llanto que me queda, sobre una misma anécdota acumula las versiones, que son como profundizaciones de la memoria: pues los momentos con la persona amada nunca fueron perfectos y se los quiere rectificar en la inagotabilidad de las alternativas. Es que no hay en verdad principio ni fin: como en una imagen holográfica, en cada parte está contenida la obra entera: esa obra cuya salvaje libertad de composición pareciera hacerla inabarcable. Infinitamente podemos dividirla, sin observar atenuación de su contagio emotivo. Por eso se mueve Armas Alfonzo sin esfuerzo y sin intención de virtuosismo desde el cuento de una línea hasta la novela completa, y ésta se extiende torrencialmente conectándose con los momentos y los seres de toda una obra. En un guiño, atisbamos esa eternidad que compendia todas las direcciones del acontecer.

\section{UBICUIDAD DE LA ANGELACIÓN}

Tampoco ha querido Armas Alfonzo, salvo en uno que otro relato temprano, hacer un contrapunto entre planos espaciales distintos, técnica literaria que, según Hauser, procede del montaje cinematográfico o ha sido al menos prestigiada por él. Clarines es tierra de linternas mágicas: sálvela el Omnipotente del Cinemascope, así como hasta ahora le ha ahorrado la tarjeta postal. La linterna mágica supone la combustión, la titilación, el color desvaído, el tiempo humano que elige y descarta láminas. También, la creación de un espacio donde se dan la mano todos los espacios, porque allí, como en el ojo, como en el Aleph, convergen todos los espectáculos. El haz narrativo de Armas Alfonzo, como el de una linterna mágica, alumbra con insistencia una sola área geográfica. No es necesario convocar el paisajismo turístico ni a la descolocación para insuflar en ella el infinito. Un relato de los hermanos Strugaskin — sobre el cual rodó Tarkovski un enigmático film - narra la internación de tres hombres en una zona donde el espacio está invisiblemente torcido y todos los caminos de escape conducen al centro. Aun los relatos de Armas Alfonzo que no suceden en Unare - varios de Los desiertos del ángel-están contagiados de él, como si no fuera una localidad, sino un pulso de la vida, un modo de ser o una infección. Por esta estricta e irreductible provincialidad, puede ya haber Clarines en cualquier parte. La clave de la paradoja es un sentimiento.

\section{AMOR}

Lo menos pensable era que de tales desolaciones surgiera al fin - y cuán inesperada en nuestra literatura - una narrativa del amor; la de Cada espina, tres historias de amor y Este resto de llanto que me queda. ¿Será que amor es desolación? O es quizá el empecinamiento con el cual investimos lo trivial de luminosidad. Apenas Manuel Vicente Romerogarcía y José Rafael Pocaterra habían cursado en nuestra literatura este tema, 
que en otros quedó sustituido por el sermón positivista, el spleen de la señorita engreída o la lubricidad animal. En los estériles osarios del tiempo, Armas Alfonzo hace florecer el amor: pasiones inmóviles, porque la frustración acumula por siempre deseo en el cuerpo detenido hasta convertirlo en memoria, y a la memoria en dolor: en espina. Como el propio Armas Alfonzo confesara en el foro "Literatura y Recuerdo", al cual lo invité en el ya lejano 1981:

\begin{abstract}
Me cuesta trabajo aceptar división entre literatura y recuerdo porque los recuerdos son parte del hombre: sí, de su realidad. Perdurarán los libros donde el hombre puso lo propio, lo simple lo que él no podía separar de sí .... No he tenido que buscar nada, ni siquiera en mí mismo, porque ellos son yo mismo, momentos de la vida de mi pueblo. Tuve el privilegio casi divino de vivir un tiempo donde sexo y muerte, inundación y guerra civil, eran hechos de cada hora: el amor nos llegaba por la vía más sencilla, no por los libros sagrados ni por las láminas que en vez de pecado son placer. El sexo era la unión corriente de todas las criaturas que poblaban ese universo. La muerte llegaba por mil vías, no siempre sin dolor, pero a nadie escandalizaba ni sorprendía ....
\end{abstract}

No importa entonces que el recuerdo opere por la vía atroz de la herida. La única rebelión posible contra la marcha triunfal de la muerte, es ese otro nombre del amor que es la memoria.

Quizá toda pasión, y toda obra, no son más que sus cicatrices.

\title{
Las Alas - del PUNTo de Vista a la visión
}

La obra de Armas Alfonzo no es manejable con las pinzas de la sociología ni con las de la ética y acaso menos con las de la estética: siempre estará más allá. De la literatura sólo me interesan los efectos que operan fuera de la aparente explicación. Entre ellos, el milagro angélico de concitar los elementos de la visión - totalidad, perennidad y ubicuidad - con los gastados signos del alfabeto. Intentemos la macabra operación de entender el hechizo al mismo tiempo que estamos sujetos a él. Todo vuelo es posible por la fragilidad de las alas que lo emprende.

Como inteligentemente dice Víctor Tacca, la mayoría de los problemas de la narrativa contemporánea se clasifican si formulamos la misma pregunta que cuando atendemos el teléfono: ¿Quién habla? Hemos visto que durante mucho tiempo en la literatura venezolana habló un Autor-Dios impersonal, situado fuera y por encima del relato, culto en lo estilístico y positivista en lo ideológico, que sólo se aproximaba a su sujeto para mejor marcar la distancia con él. Si bien en algún momento Armas Alfonzo - como todos nosotros- jugó a ser este narrador ausente, desde que inaugura su estilo maduro se aposenta en los ámbitos de lo narrado de manera tan cabal que no necesita anunciarlo con estridencias. Así, en el párrafo inicial de El osario de Dios, después de que el autor enumera en una aparente tercera persona que «había una cruz en La cruz de Belén, otra en la Cruz del Zorro ... sin contar las tres de El Calvario, donde se rascaban el lomo los chivos en caso de necesidad:, la misma voz inquiere, en una poderosa primera persona del plural: “¿Qué nos iba a pasar?” 
Estas escasas cinco líneas establecen una estrategia de enunciación del relato que ya no variará. Aunque haya textos escritos en tercera persona, presentimos - sabemosque los cuenta uno de los personajes. Y uno que compartirá el terrible destino común, aunque a veces, sólo establece su presencia indicando discretamente que reside en el mismo lugar que sus criaturas, como cuando dice:

Cacuro no es de aquí; a Cacuro lo trajo una revolución y él se quedó porque esto se le parece a su origen. (El osario 6).

Pero no sólo es un hablante arraigado en el mismo esto y aquí de sus hechuras: comparte la falibilidad, las hesitaciones de ellas:

El cereipo aspiraba a nube verde. Entre los palos de cereipo había uno que floreaba morado. Entonces no era cereipo. Era acapro. Majomales. Guaritotales. Mayales. (El osario 21).

Por momentos interpela a los lectores como a conocidos con quienes comparte ya el escenario narrativo. Al mencionarles el Cristo de la Iglesia de Clarines, añade, demostrativamente: "Ahí pueden verlo" (El osario 59).

Este narrador a veces se nos identifica como un testigo infantil; pero no tiene ambición de convertirse en protagonista ni de reducir lo contado a memoria personal: cuando no puede evitar la autobiografía se refiere a sí mismo con el seudónimo de Sixto y en distanciante tercera persona, porque:

Del abuelo Ricardo el niño ha aprendido que de aquello que a uno le es querido no debe hacerse escándalo, igual que con el nombre de uno. (Cien máuseres, ninguna muerte y una sola amapola 15 ).

O bien se aproxima apenas al umbral de la segunda persona:

Tú, niño adolescente, escribes en tu cuaderno la tarea que el maestro Lorenzo nunca te puso. Escribes con letra serena tu plana de ese día del mar de Píritu (Este resto de llanto que me queda 50).

Estableciendo entonces, en algunos casos, la distancia del diminutivo, para recordarnos que el paradójico decurso temporal que envejece lo narrado convierte al narrador en niño:

Los azulejos comieron y mamá duerme. Ahora los ángeles van a decir amén. Ya tú los vas a oír decir amén, Sixtico. (El osario 158).

Pero la mayoría de las veces prefiere diluirse entre la colectividad, asumiendo la primera persona del plural, y presentándose más como escucha colectivo de historias que como inventor de ellas. 
Fernando Madriz Galindo que lo presenció, nos lo contaba entre un olor de damadenoche nocturno e interminable. (El osario 39$)$.

E incluso ante una niña de inconmesurable hermosura, que seguramente despierta una pasión personal, se mantiene esta identidad colectiva:

El paso de la niña Pieretti por el río, a aquella hora del baño de la escuela, fue un suceso que se recordó años y años. Nos conmovió, sobremanera, su mirada azul (Los desiertos del ángel 25).

Este narrador individual que quiere fundirse con su comunidad asume el habla de ella, sin entrecomillarla, ni destacarla en cursiva ni engastarla como interferencia. Nombra con soltura árboles y pájaros con sus apelativos populares, sin pedantería taxonómica. Para él las paredes de barro son pajareque, y las anécdotas, güiripas, sin que suenen a léxico criollista. $\mathrm{Al}$ asumir el lenguaje de sus criaturas, se ha vuelto una misma y única cosa con ellas.

\section{DE LA PARTICULARIDAD A LA TOTALIDAD}

Estos personajes asumen por otra parte una hiperrealidad muy diferente de la prestada por el mero documentalismo. Ciertamente, algunos están tomados del natural, pero ello no bastaría para darles vida. Su verismo es efecto de un procedimiento literario. Ante todo, tienen una patronímica específica. Donde otro escritor podría decir simplemente el hombre, o el arriero, Alfredo Armas Alfonzo declara nombre, apellido, sobrenombre, parentela y a veces hasta sitio de nacimiento:

Vicente María de Armas y su esposa, Manuela Matos, vivieron siempre en El Mamey, a un paso de Guanape (Cien máuseres ... 87).

La noticia de la muerte de Consuelo Ricardo, la hija de Mortimer Ricardo, sumió a Merceditas Alfonso en la aflicción (Cien máuseres ... 205)

Lourdes Armas, nieta de Rojas, mientras hacía nacer las suyas con corazón de retazos de telas de muñecas, se preguntaría, se estaría preguntando ahora, si habría verdad en eso que contaban de que hubo una paloma que talló Don Cándido que cobró vida y ascendió esas transparencias azules de diciembre (Angelaciones 121)

El personaje surge así sembrado en una tierra y una sangre y por tanto arraigado (indesarraigable). Estos seres, como las proliferantes humanidades de los cuadros de El Bosco o de Brueghel, están dispersos en la vasta composición abierta de la obra. Muy raramente domina alguno de ellos, salvo por su participación repetida en varios núcleos anecdóticos; jamás se convierte en tema dominante, hasta opacar a los restantes o hacer que éstos existan exclusivamente en función suya. Pues la megalópolis, con su multitudinaria soledad, facilita y quizá impone la narrativa centrada en el protagonista cuyo rostro oculta el universo. Mientras que en la aldea se siente la múltiple respiración de los seres. Ninguno de ellos, humano, animal o planta puede ser eliminado de la vida sin que el relente de su existencia lo sobreviva y perturbe. En el matadero de Guanape, 
cuando una res es sacrificada, las sobrevivientes olfatean la sangre y prorrumpen en un mugido que los lugareños interpretan como un llanto. De igual manera se inclinan los hombres sobre sus osarios. Me han contado que la tumba más adornada es la anónima huesa del peón a quien mandó a matar el caudillo Deogracias Itriago. No falta quien prefiera morir en el pueblo, porque siempre habrá alguien que adorne la lápida el Día de Difuntos. Se explica así el anónimo pero presente narrador en la vasta red de sus criaturas: en la aldea nadie es totalmente individual; como en el lancinante verso de John Donne, ningún hombre es una isla. Y al tratar de uno, se habla inevitablemente de nosotros, de todos.

\section{De la ANÉCDOTA A LA PERENNIDAD}

El lector que se adentra en esta jungla de seres lo hace con la sensación de que el tiempo es misteriosamente perturbado: mientras el texto casi siempre le informa que lo narrado aconteció en años remotos, su recuerdo persiste hasta invadir el presente y amenazar la ocupación del porvenir.

Pero es que, en la narrativa, la diferencia sensible entre pasado, presente y futuro depende de un recurso que es la progresión del relato; el narrador común dosifica sus informaciones para trasladarnos desde un inicio, pasando por las consabidas estaciones del planteamiento, la crisis y el nudo dramático, hasta la necesaria resolución. Al igual que los místicos, Armas Alfonzo une todas las dimensiones del devenir agolpándolas en un solo instante, y esto lo logra apretando en un solo párrafo inicial, a veces en una frase, todo lo que en el relato hay de anécdota:

Nomeolvides Blanco, la hija de Narciso Blanco, comerciante de sal y de pescado, me mandó a decir una vez, un Jueves Santo de 1934, con hermanito menor, que le escribiera un papelito de amor. Yo no lo hice por pena, y desde entonces temía encontrarme con ella (El osario 58).

Después de esta introducción, que agota el argumento, el relato sin embargo sigue, pero sólo para volver sobre sí mismo, para explorar el sentir de los personajes o su mundo sensorial, o los recovecos laterales de aquel tiempo ya clausurado, y que, sin embargo, revive con fulgor inaudito porque el narrador a veces lo evoca paradójicamente en presente literario:

Nomeolvides Blanco es la mejor alumna de la escuela de hembras y colecciona ampolletas vacías para hacer cortinas. Las de su casa son todas así y cuando alguien entra o sale de las habitaciones de la casa de Nomeolvides Blanco deja tras de sí un susurrante rumor de vidriecitos golpeados. (El osario 58 ).

Para concluir frecuentemente con un último párrafo, o coda, que no trae ninguna revelación argumental ni desenlace de última hora, sino que es como una iluminación secreta del sentido del cuento, una epifanía, clausura del pasado que revivió, y por tanto doliente epitafio: 
Narciso Blanco aspira a casar a su hija con alguien de porvenir y en Casa saben que el porvenir no consiste de necesidad.

Porque, con frecuencia, la anécdota, sangrienta o dolorosa o compleja, ha girado sobre este oculto vórtice, que es casi siempre íntimo o estético. Así, tras una estrepitosa batalla que estropea las coronas de flores de un banquete nupcial:

Rufa Anato tan desgraciada lloraba por el trabajo que le costó reunir los azahares ( $E l$ osario 4).

O, cuando llega a su fin la larga agonía de una niña muy pálida:

En una blanca, con velo de punto sobre el rostro, la metieron y ni siquiera así adquirió otro color (El osario 45).

Pero sí como el tiempo es detenido por la brevedad fulgurante, también puede ser fijado aprisionando al personaje en medio de una proliferante enumeración de objetos inanimados, suerte de naturaleza muerta verbal que además, por su ritmo de letanía, tiene función encantatoria:

Y cuando nos metimos a la casa donde había vivido el abuelo Ricardo, y Chipe me enseñó el cuarto de él, con el techo desplomado, y las alcayatas donde tenía colgado su moriche pariaguanero con el hierro de las alcayatas forradas con liencillo para que no crujiese el hico, Maura Tonito se apareció o ya llevaba tiempo allí, junto a las matas profusas de azahar de la India, entre los esbeltos pilares sexagonales de madera de corazón de pui todavía enteros, junto a los estantes donde se exhibían los cortes de tela del negocio, junto a la piedra de amolar la espada y una sección de la silleta en que él se sentaba a coger el sol mañanero después que le dio lo que le dio en la cara, junto a la puertecita del baño donde todavía seguía intacto el excusado de hoyo, y creciéndole en el quicio demasiadas matas de putica de la planca, la puerta de una sola hoja desvencijada (Cada espina18).

El procedimiento de clausurar todo posible decurso narrando de una vez lo que ha de venir es usado incluso en su novela. Este resto de llanto que me queda, de modo que el lector sepa, al adentrarse en ella, que se mueve en un tiempo ya acontecido y, por lo mismo, irrevocable a la vez que perenne:

La novela de un muchacho que no sobrevivió con su dulzura intacta a la muerte de la protagonista no podría ponérsele de título a un libro por más que ella te lo hubiera pedido (Este resto ... 11).

Por lo cual el terrible acontecimiento que llena el capítulo 61 no es sorpresa, y ni siquiera fin (acaso comienzo de lo que ya no tendrá término):

Dijo que el agua estaba oscura y que la playa parecía un cementerio, que había días así y que nadie se daba cuenta. En esto, mientras se cubría con el paño se fue hacia 
delante y cuando él y la prima de ella la voltearon tenía arena en los ojos y ya no respiraba. Se había muerto tierna y dulcemente (Este resto ... 112).

Y la coda o epílogo de la novela se adentra hacia un estático y silencioso futuro: hacia el día terrible en que el narrador sólo podrá expresarse por el verso de otro, porque su propia voz ya estará ausente:

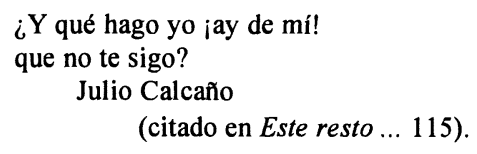

De La SOBRIEDAD A LA UBICUIDAD

Sabemos así cómo por dilución enunciativa de la individualidad en la multitud de los seres y por detención o eternización retóricas del instante, parecería que todos los distintos personajes habitan una misma conciencia y un mismo tiempo. Otro golpe maestro literario los ubica en un único espacio, no sólo geográfico - pues varias de sus historias suceden fuera de la región de Unamuno- sino también vivencial.

$\mathrm{Si}$ intentamos recordar las impresiones que nos causa la obra de Armas Alfonzo, quizá encontraremos como dominante la sensación de aridez: una heremítica, por momentos dolorosa austeridad cuyo más relevante mérito es que no surge ni de una realidad geográfica ni de una descripción denotativa.

Pues parece ser que la devastación del paisaje de la cuenca de Unare se debe a los traficantes de madera que la arrasaron a mediados de este siglo. Podemos concebir entonces que los modelos que inspiraron personajes de Armas Alfonso se movieron en medio de verdores lujuriantes y pájaros tornasolados. Todavía es el edénico mundo germinativo de los relatos de Cada espina. Para revelarnos el ascetismo de su mundo interior, Armas Alfonzo creó alrededor de ellos un universo desolado cuyo código - no su descripción- es una palabra llevada a una contención sobrecogedora. Para evocar el desierto le basta con no nombrarlo.

El artista maduro tiende a dosificar sus efectos. En las fulgurantes últimas marinas de Turner, hay cada vez menos colores y mayor luminosidad. Similar efecto paradójico logra Armando Reverón escatimando la materia que aplica a sus telas: éstas resplandecen más por la ausencia que por la presencia de vehículos plásticos. Haciendo cada vez más escueta la narración, Alfredo Armas Alfonzo nos transmite una naturaleza desnuda: paisaje árido, cielo sin nubes, mar sin naves, vidas sin goces, no son un efecto de la descripción, sino de la falta de ella. El relato que se agota en dos párrafos y deja con ganas de seguir leyendo, equivale al pozo que se bebe en dos sorbos y sólo deja la sed. Cuando por fin las materias de la sequedad aparecen, lo hacen como metáforas, es decir como puro lenguaje.

El pelo de mazorca seca, la piel de hoja que resecó la resolana, la uña del pie como el pico del gavilán y el otro paso acompasado de madera de palo que el cerote untó y reuntó de sudores y saliva (Angelaciones 24). 
Con la misma reticente ascesis es capaz de contar toda una biografía espiritual en la última lacerante frase del párrafo que describe las habilidades manuales de un artesano:

Don Cándido Rojas labró también el crucificado de la iglesia de Clarines: ahí pueden verlo. Las manos y los pies son como de verdad pero la peluca le tapa la cara y hay que apartar los rizos para descubrirle los ojos cerrados y la boca desdeñosa. Esa peluca es el pago de una promesa. Don Cándido Rojas pues tenía habilidad para el sufrimiento (El osario 59).

\section{VISIÓN MÚLTIPLE DE ÁNGELES}

La habilidad para el sufrimiento, como la que requiere el amor, no es sólo la de experimentarlo, sino también la de contagiarlo. No en balde atraviesa toda la obra de Armas Alfonzo, por alusión o por directa mención, la figura del Ángel, vale decir, del mensajero. No otra cosa son sus reiterativas niñas muertas: pero también las palabras. Al extremo de que para la imaginación popular, toda pausa en la conversación anuncia el paso de un querube. Perdidos en nuestra desesperada soledad de osarios, muertes, espinas y llantos, para despertar la complicidad no disponemos más que del signo. Cuando éste remonta el vuelo a pesar de su menesterosa fuerza ascencional de palabras, sentimos que la habilidad ha convertido la congoja en espíritu celeste.

\section{Obras de Alfredo Armas Alfonzo citadas}

El osario de Dios. Cumaná: Editorial Universitaria de Oriente, 1969.

Cien máuseres, ninguna muerte y una sola amapola. Caracas: Dirección de Cultura, Universidad Central de Venezuela, 1975.

Angelaciones. Caracas: Ediciones Equinoccio, Universidad Simón Bolívar, 1979. Este resto de llanto que me queda. Caracas: Alfadil Ediciones, S.A.,1987.

Cada espina: tres historias de amor. Caracas: Monte Ávila Editores, 1989.

Los desiertos del ángel. Caracas: Monte Ávila Editores, 1990. 